\title{
Síndrome de Hipoestesia Mentoniana (Numb Chin Syndrome) asociado a Carcinoma Epidermoide Pulmonar
}

Gabriel González Roa ${ }^{a}$

a Especialista en Medicina Familiar y Comunitaria. Centro de Salud Vélez-Málaga Norte UGC, Área Sanitaria Este de MálagaAxarquía, Servicio Andaluz de Salud (España).

Correspondencia: Gabriel González Roa, c/ San Isidro 1, Vélez-Málaga, 29700 - Málaga (España). correo electrónico: gagoro@telefonica.net

Recibido el 15 de noviembre de 2010.

Aceptado para su publicación el 22 de diciembre de 2010.

\section{RESUMEN}

El síndrome del mentón entumecido (numb chin syndrome) en ocasiones representa una patología banal, sin embargo, es frecuente su asociación con procesos malignos. Se presenta un caso de carcinoma epidermoide pulmonar cuya primera manifestación fue ésta, detectada en la consulta de Atención Primaria, y se realiza una breve revisión bibliográfica. Palabras Clave. Hipoestesia, Neoplasias Pulmonares.

\section{ABSTRACT}

Numb chin syndrome associated with squamous cell carcinoma of the lung

Numb chin syndrome can occasionally be a banal disease; however it is often associated with malignant processes. We present a case of squamous cell carcinoma of the lung the first manifestation of which was numb chin syndrome; detected at a Primary Care visit. A brief review of the literature was also performed.

Key words. Hypesthesia, Lung Neoplasms.

\section{INTRODUCCIÓN}

El síndrome del mentón entumecido (numb chin syndrome) no es de presentación frecuente en la práctica clínica, y en ocasiones representa una patología banal. Sin embargo, su frecuente asociación con procesos malignos, y su carácter de indicador de mal pronóstico, hacen necesario mantener un alto grado de sospecha y abordar la búsqueda sistemática de un proceso maligno subyacente. Se presenta un caso de carcinoma epidermoide pulmonar cuya primera manifestación fue ésta, detectada en la consulta de Atención Primaria, y se realiza una breve revisión bibliográfica.

\section{OBSERVACIONES CLÍNICAS}

Paciente de 72 años de edad con los siguientes antecedentes personales: ex fumador de 20 paquete/año hasta hace diez años, sin recaídas en el consumo, bebedor ocasional, intervenido de colecistectomía hace 15 años, diagnosticado de EPOC tipo bronquitis crónica hace 15 años, en tratamiento con broncodilatadores inhalados desde entonces, con exacerbaciones aproximadamente anuales que han requerido tratamiento antibiótico.

Acude a consulta programada en el marco del proceso asistencial de EPOC, para valoración clínica y de su espirometría anual. No ha presentado exacerbaciones de su proceso de base desde la última revisión, y la espirometría realizada no muestra cambios significativos respecto a la anterior (FVC $48 \%$, FEV1 39\%). No refiere hemoptisis, y ha recibido la vacunación antigripal la semana anterior.

A la exploración, se trata de un paciente con ligera obesidad, bien hidratado y perfundido, que presenta una auscultación respiratoria compatible con su 
patología de base y una saturación de O2 de 96\% respirando aire ambiente.

Incidentalmente el paciente refiere que desde hace una semana ha notado una zona de insensibilidad cutánea que afecta a la mitad izquierda del mentón y borde inferior del hemilabio (figura 1). La hipoestesia le ha provocado cortes inadvertidos durante el afeitado. Niega haber sufrido ningún otro traumatismo sobre la zona, ni manipulaciones odontológicas.

No se observa ningún déficit motor ni desviación de la comisura bucal. La motilidad de párpados y lengua es normal y en la exploración endobucal no se encuentran alteraciones significativas.

Dados los antecedentes del paciente, y ante la sospecha de un proceso maligno de posible origen pulmonar, se solicita radiografía simple de tórax (figura 2), que muestra una masa localizada en lóbulo inferior izquierdo compatible con carcinoma broncopulmonar, por lo que el paciente es derivado directamente al servicio de Neumología para continuar el proceso diagnóstico-terapéutico.

Tras etiquetarse como carcinoma epidermoide estadio IIIB, inicia quimioterapia con carboplatino y gemcitabina, seguido de pauta de radioterapia, tras lo que desaparece totalmente la clínica de hipoestesia cutánea. Seis meses después, en revisión radiológica, se detecta hidroneumotórax izquierdo que requiere nuevo ingreso para drenaje y posterior fisioterapia respiratoria.

Actualmente permanece en tratamiento con corticoides inhalados, terbutalina y tiotropio, además de oxigenoterapia domiciliaria. Mantiene calidad de vida similar a la previa, aunque precisa ayuda para algunas actividades de la vida diaria.

\section{COMENTARIOS}

El síndrome de hipoestesia mentoniana, neuropatía mentoniana, numb chin syndrome ${ }^{1}$ en la literatura anglosajona o signo de Roger $^{2}$ en la francófona, fue descrito por Bell en $1830^{3}$ en una paciente afectada de cáncer de mama. Corresponde a una zona de anestesia/hipoestesia cutánea referida al territorio inervado por el nervio mentoniano, rama terminal del nervio dentario inferior, procedente a su vez de la tercera rama del trigémino.

Desde las primeras descripciones, se han sucedido las publicaciones de casos aislados o pequeñas series, en que aparece relacionado con un amplio grupo de procesos que podemos clasificar como:

a. Procesos benignos: absceso odontogénico ${ }^{4}$, anestesia local, trauma local, osteomielitis, tumores benignos, toxicidad por bifosfonatos ${ }^{5}$, neuropatías sensitivas no tumorales ${ }^{6,7}$.

b. Enfermedades generales: amiloidosis sistémica, conectivopatías ${ }^{8}$, sarcoidosis, anemia falciforme $^{9}$, esclerosis múltiple, diabetes mellitus, infección por VIH.

c. Procesos malignos: linfomas ${ }^{10}$, leucemias ${ }^{11,12}$, carcinoma pulmonar ${ }^{13,14,15}$, adenocarcinoma de próstata ${ }^{16}$, tumores malignos de cabeza y cuello, melanoma ${ }^{16}$, carcinoma de mama $^{17}$, cáncer de endometrio, carcinoma gástrico ${ }^{18}$ y esofágico ${ }^{19}$.

Se han propuesto diversas hipótesis para aclarar la patogenia del síndrome, aunque en la mayoría de los pacientes no se puede explicar con precisión ${ }^{20}$. La compresión del nervio dentario inferior o del mentoniano por metástasis mandibulares, la diseminación hematógena o linfática, la afectación intracraneal del trigémino por metástasis de la base del cráneo o la presencia de implantes leptomeníngeos a distancia figuran entre las más frecuentemente descritas.

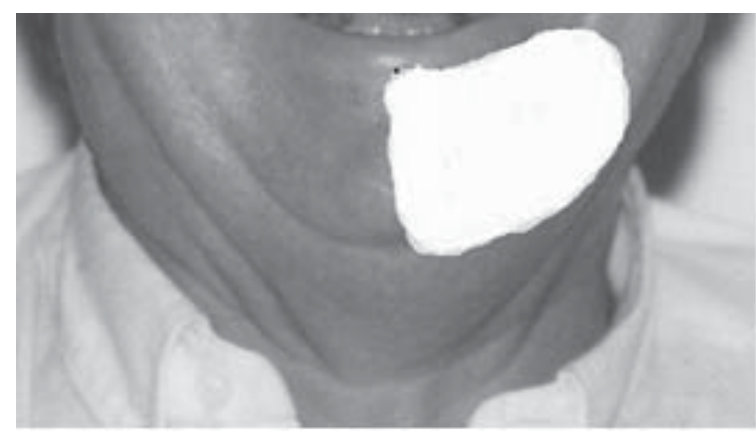

Figura 1. Distribución de la zona de hipoestesia en el mentón. 


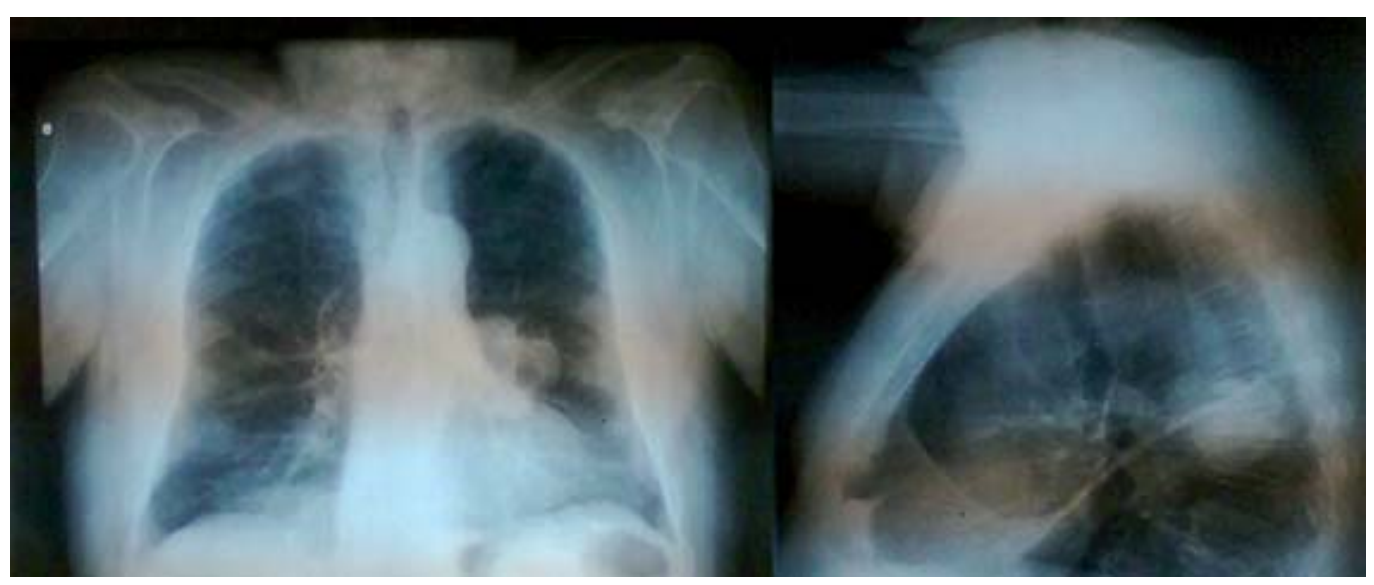

Figura 2. Radiografía de tórax: masa pulmonar en lóbulo inferior izquierdo.

En la mayoría de los casos se describe la desaparición de los síntomas sensitivos con el tratamiento específico del proceso maligno de base ${ }^{21}$, y se considera su aparición en pacientes previamente diagnosticados de cáncer como un signo de mal pronóstico ${ }^{4,8,21}$.

En conclusión, se hace necesario mantener un alto grado de sospecha clínica ante la aparición de cuadros en apariencia banales, sobre todo en el nivel de Atención Primaria ${ }^{22}$, que pueden ser indicativos de un proceso maligno subyacente ${ }^{13}$.

\section{BIBLIOGRAFÍA}

1. Calverley JR, Mohnac AM. Syndrome of the numb chin. Arch Intern Med. 1963;112:819-21.

2. Roger H, Paillas J. Le signe du mentonnier (paresthesie et anesthesia unilateral) revelateur d'un processus metastatique. Rev Neurol. 1937; 2:751-2.

3. Furukawa T. Charles Bell's description of numb chin syndrome. Neurology. 1988; 38:331.

4. Lossos A, Siegal T. Numb chin syndrome in cancer patients: Etiology, response to treatment, and prognosis significance. Neurology. 1992; 42:1181-4.

5. Sierra Hidalgo F, De Pablo-Fernández E, Correas-Callero E, Villarejo-Galende A. Numb chin syndrome caused by biphosphonates-induced osteonecrosis of the jaw. Rev Neurol. 2009; 49(4):190-2.

6. Blau JN, Harris M, Kennett S. Trigeminal sensory neuropathy. N Eng J Med. 1969; 281:873-6.

7. Peñarrocha M, Alfaro A, Bagan JV, Lopez-Trigo J. Idiopathic trigeminal sensory neuropathy. J Oral Maxillofac Surg. 1992; 50:472-6.

8. Alfaro-Giner A, Peñarrocha-Diago M, Bagan-Sebastian JV. Orofacial manifestations of mixed connective tissue disease whit an uncommon serological evolution. Oral Surg Oral Med Oral Pathol. 1992; 73:441-4.
9. Konotey-Ahulu FI. Mental-nerve neuropathy: a complication of sickle cell crisis. Lancet 1972; 2:388.

10. Baskaran R. Numb chin syndrome-a reflection of systemic malignancy. Word J Surg Oncol. 2006; 4:52.

11. Çetiner S, Aspaslan C, Güngör N, Koçak U. Tooth pain and numb chin as the initial presentation of systemic malignancy. Tr J Med Sci. 1999; 29:719-22.

12. Hiraki A, Nakamura S, Abe K, Takenoshita Y, Horunouchi Y, Shinohara M, Shirasuna K. Numb chin syndrome as a initial symptom of acute lymphocytic leukemia. Oral Surg Oral Med Oral Pathol Oral Radiol Endod. 1997; 83:555-61.

13. Marco Cairó FJ, Sender Palacios MJ, Ferrás Murcia JV. Hipoestesia mentoniana en paciente fumador. Rev Clin Esp. 2008; 208(4):205-8.

14. Carratalá J, Prat J, Galarza I, Mitjavila F. Neuropatía mentoniana asociada a carcinoma pulmonar de células pequeñas. Rev Clin Esp. 1987;180(5): 288-9.

15. Laurencet FM, Anchisi S, Tullen E, Dietrich PY. Mental neuropathy: revision of five cases and review of the literature. Crit Rev Oncol Hematol. 2000; 34(1):71-9.

16. Burt RK, Sharfman WH, Karp BI, Wilson WH. Mental neuropathy (numb chin syndrome): a harbinger of tumor progression or relapse. Cancer. 1992; 70:877-81.

17. Horton J, Means ED, Cunningham TJ, Olson KB. The numb chin in breast cancer. J Neurol Neurosurg Psychiatr. 1973; 36:211-6.

18. Atienza MR, Varela JM. Neuropatía mentoniana como síntoma inicial del carcinoma gástrico metastásico. Neurología. 2008; 23(1):71-2.

19. Narendra H, Ray S. Numb chin syndrome as a manifestation of metastatic squamous cell carcinoma of esophagus. J Can Res Ther. 2009; 5:49-51.

20. Massey EW, Moore J, Schold SC. Mental neuropathy from systemic cancer. Neurology. 1981; 31:1277-81.

21. Evans RW, Kirby S, Purdy A. Numb chin syndrome. Headache. 2008; 48:1520-4.

22. Sweet JM. The numb chin syndrome: a critical sign for primary care physicians. Arch Intern Med. 2004; 164:1347-8. 